\title{
Tribological Behavior of Hastelloy C and Refractalloy 26
}

\author{
A. Varela, A. García, J. L. Mier, F. Barbadillo, and C. Camba \\ Department of Industrial Engineering II, University of A Coruña, C/Mendizábal s/n, \\ 15403 Ferrol, Spain
}

Correspondence should be addressed to J. L. Mier, jlmier@udc.es

Received 21 July 2011; Accepted 12 September 2011

Academic Editors: R. Brighenti and X. Yang

Copyright () 2011 A. Varela et al. This is an open access article distributed under the Creative Commons Attribution License, which permits unrestricted use, distribution, and reproduction in any medium, provided the original work is properly cited.

This paper compares the abrasive wear behaviour of two nickel alloys (Hastelloy and Refractalloy). Wear was calculated by weight loss using pin-on-disk tests that were carried out at certain values of load, speed, and temperature range. The study is completed with metallographic observations at different temperatures of the wear tracks before and after the tests. Also, the variation of the coefficient of friction with temperature is calculated in the two alloys studied.

\section{Introduction}

During their service life, it is essential that high-temperature alloys resist aggressive environments without deterioration of mechanical properties. Abrasive wear is a major concern here because it is closely related to the surface hardness of a material.

A characteristic of nickel superalloys is that they are able to maintain these properties at a temperature above $600^{\circ} \mathrm{C}$ without losing their surface stability. There are nickel-base superalloys strengthened by solid solution like Hastelloy X. However, precipitation hardening alloys such as Refractalloy 26 or Hastelloy $\mathrm{C}$ are preferable for high temperature applications. Austenite is the term used to describe the face-centered cubic (fcc) phase of these alloys. The main precipitate is $\gamma^{\prime}$ phase that corresponds with the intermetallic compound $\mathrm{Ni}_{3} \mathrm{TiAl}$, although carbides of different stoichiometries may appear. The precipitation of $\gamma^{\prime \prime}$ phase $\left(\mathrm{Ni}_{3} \mathrm{Nb}\right)$ in superalloys containing niobium is also possible.

There have been few studies on the abrasive wear of nickel superalloys at high temperatures [1-3]. In general, the resistance to abrasive wear of these alloys increases with their content of hard phase [4]. Nevertheless, other factors seem to affect significantly this resistance. These include the size and shape of the precipitate within the microstructure, as well as the size and shape of the abrasive particles [5].

\section{Material and Methods}

This study was carried out on two nickel-base superalloys: a Refractalloy 26 and a Hastelloy $\mathrm{C}$ as cast. Their composition in weight percentage, determined by $\mathrm{X}$-ray fluorescence, is listed in Table 1.

Pin on disk tests were carried out to determine behavior under abrasive wear, in accordance with ASTM G99 "Standard test method for wear testing with a pin-on-disk apparatus" [6]. No lubrication was used.

Tests were accomplished at $300 \mathrm{rpm}$ of speed with a gyration radius of $8 \mathrm{~mm}$ and a load of $10 \mathrm{~N}$. $4 \mathrm{~mm}$ diameter hardened steel ball 52100 served as pins. The test lasted 18000 revolutions ( 1 hour), and it was performed at room temperature, $100,200,300$, and $400^{\circ} \mathrm{C}$. The test temperature corresponds to the temperature measured in the oven that contains the sample and pin. For each test, preheating to a suitable temperature was done and, after a stabilization and homogenization period of 15 minutes, a one-hour wear cycle began. Finally, the samples were left to cool gradually. They all presented an average rugosity value (Ra) below $0.30 \mu \mathrm{m}$. These tests helped to determine the friction coefficient for the superalloys at different temperatures determined versus friction force and pressure in every moment of the test and the resistance to wear expressed as the mass loss during the wear process under controlled conditions. 


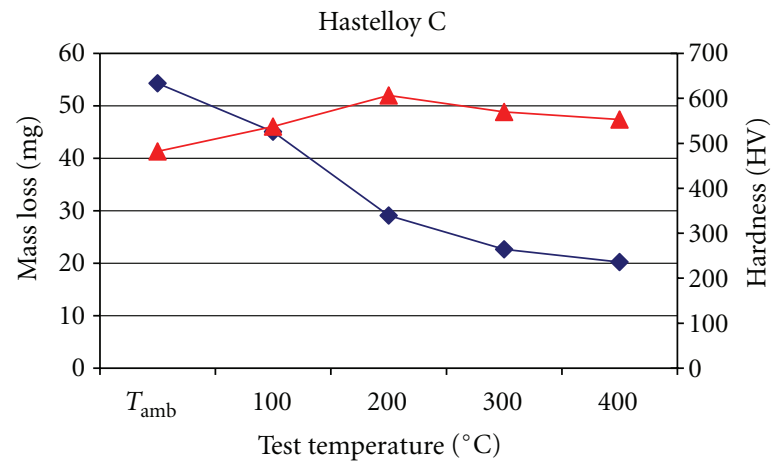

(a)

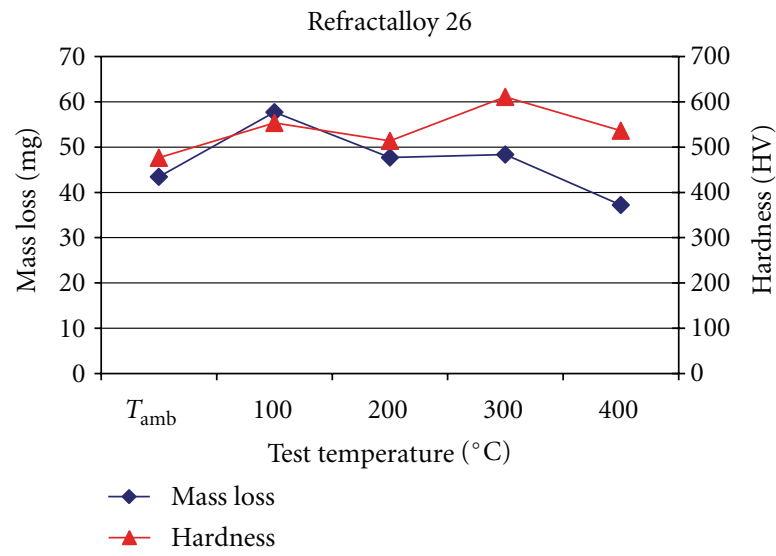

(c)

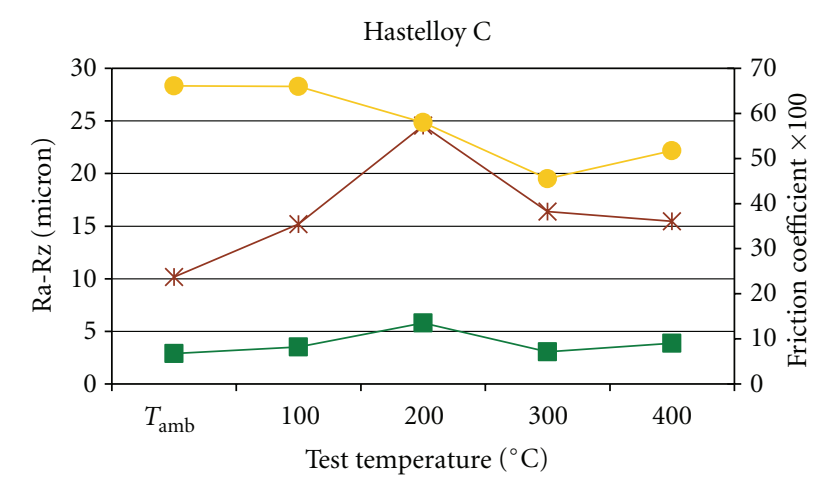

(b)

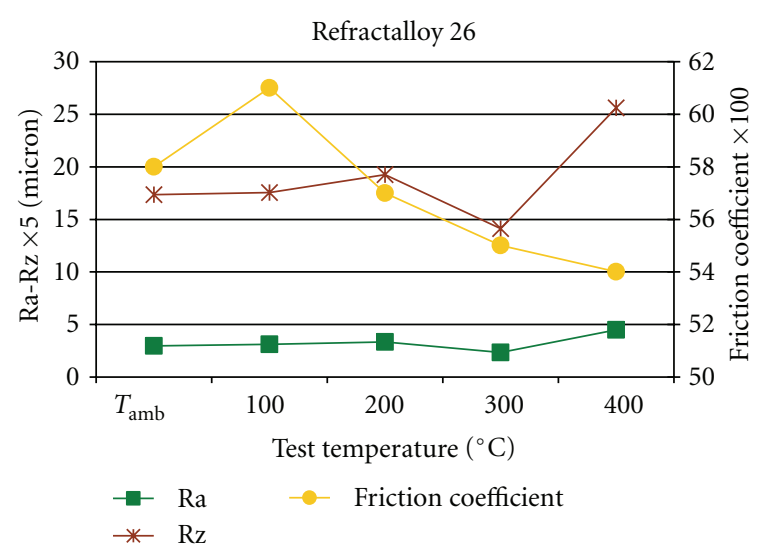

(d)

Figure 1: Results for the wear and hardness tests on the Hastelloy C and Refractalloy 26.

TABLE 1: Chemical composition of the superalloys, determined with (XRF).

\begin{tabular}{lcc}
\hline Element [\%] & Refractalloy 26 & Hastelloy C \\
\hline $\mathrm{Ni}$ & 35,800 & 56,500 \\
$\mathrm{Cr}$ & 16,500 & 14,700 \\
$\mathrm{Mo}$ & 2,510 & 14,700 \\
$\mathrm{Fe}$ & 23,000 & 5,750 \\
$\mathrm{~W}$ & 0,106 & 3,190 \\
$\mathrm{Al}$ & 0,269 & 2,810 \\
$\mathrm{Co}$ & 17,620 & 0,802 \\
$\mathrm{Mn}$ & 0,501 & 0,517 \\
$\mathrm{Si}$ & 0,103 & 0,091 \\
$\mathrm{Ti}$ & 2,668 & - \\
\hline
\end{tabular}

In order to complement these results, a study of the wear tracks was done to obtain their average rugosity ( $\mathrm{Ra}$ ) and average height of the irregularities found along ten points, $\mathrm{Rz}$, (the five highest peaks and the five lowest valleys). This parameter gives information about the irregularity of the profile. In this way, if one sample presents the same Ra value than other, but $\mathrm{Rz}$ is higher, this implies that their wear track is more heterogeneous.

Once the wear behavior of the two superalloys had been assessed at different temperatures, the hardness of both materials and that of wear zones in tribological tests was determined. Vickers microhardness measurements were taken applying a load of $200 \mathrm{~g}$ for 20 seconds. The aim here was to see if the material is hardened as a result of friction forces.

The final step was to analyze the metallographic structure of the two alloys before they were subjected to wear and the samples once they have been subjected to the thermal cycle for the wear test. The first materials were polished and etched with the white-hot reactive Kallings 2 [7], and then their microstructure was observed by optical microscopy.

\section{Results}

Figure 1 shows the results of mass loss. The values represented (as well as in case of hardness) are the average of the results obtained for the different tests in every sample. The standard deviation was calculated to determine the goodness of the results. The average value for weight loss varies among the different samples. Thus, the variation coefficient was used, establishing a value limit of 0.30 that all the results must fulfil. Moreover, those tests that do not fall within this limit were eliminated from the analysis of results. Average mass loss for the Hastelloy C (Figure 1(a)) decreases when the test temperature increases. Thus, this amount exceeds $54 \mathrm{mg}$ at ambient temperature and it reaches $20 \mathrm{mg}$ for the $400^{\circ} \mathrm{C}$ test. 


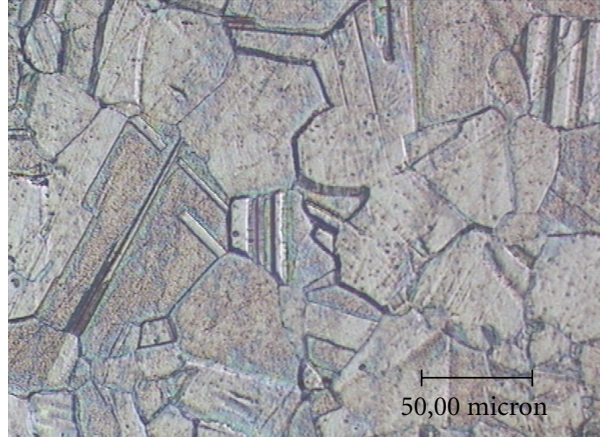

(a)

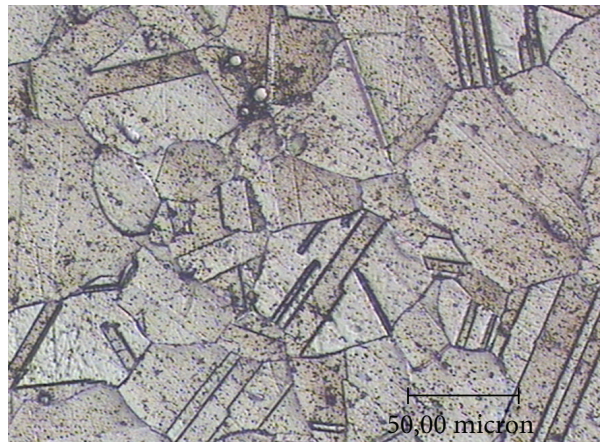

(c)

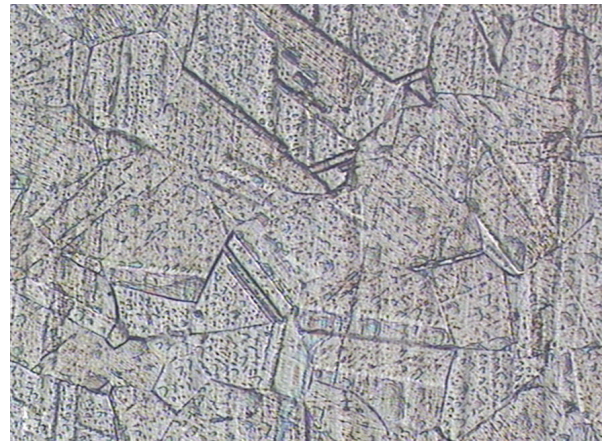

(b)

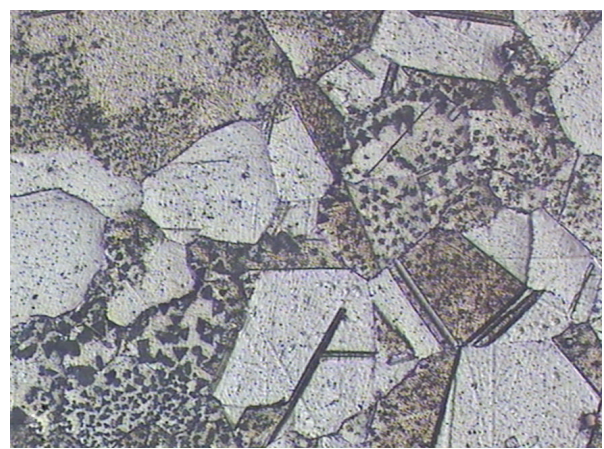

(d)

Figure 2: Microstructure of the Hastelloy C prior to testing (a) and that of the alloy subjected to the thermal cycle of the wear test at $400^{\circ} \mathrm{C}$ (b), as well microstructure of the Refractalloy 26 without modifications (c) and once it had been subjected to the thermal cycle of the same test (d).

The resultant hardness corresponds with the average hardness in the wear track left in each pin on disk test at varying temperatures. The hardness for the untested Hastelloy C is $255 \mathrm{HV}$. The friction forces generated in the wear process raise hardness to values exceeding $480 \mathrm{HV}$.

Moreover, it is possible to observe how the trend for the mass loss curve is contrary to that for hardness. Between ambient temperature and $200^{\circ} \mathrm{C}$ one can detect a drop in mass loss (or a rise in wear resistance). At the same time, the hardness of the surface subjected to wear increases. From $200^{\circ} \mathrm{C}$ upwards, the hardness slightly lessens, while the decrease in mass loss is gentler than it had been in the previous section.

The average friction coefficient during the wear tests practically remained constant. That is, the value shown in Figure 1(b) as the average value measured in each test multiplied by a factor of 100 so that it can be represented alongside other parameters. The friction coefficient follows a discernable trend similar to that of the mass loss: it increases in parallel with the wear that is produced.

The average rugosity of the wear track, $\mathrm{Ra}$, is higher as the $\mathrm{Rz}$ increases, suggesting that the rugosity profile is more irregular. By comparing the curves for $\mathrm{Ra}$ and $\mathrm{Rz}$ with the one for hardness, a similarity becomes evident. A greater rugosity is obtained for the hardest samples.

As for Refractalloy 26 (Figures 1(c) and 1(d)), the average mass loss at $100^{\circ} \mathrm{C}$ increases with respect to the one obtained at ambient temperature. Beyond this value, a decrease is detectable and becomes more remarkable at $400^{\circ} \mathrm{C}$. The same trend can be appreciated for the average friction coefficient value represented (multiplied by 100). Nevertheless, its decrease is more gradual than that of the mass. It nearly becomes constant after $300^{\circ} \mathrm{C}$.

By comparing the hardness measurements along the various wear tracks of the Refractalloy 26 with the average hardness of $461 \mathrm{HV}$ for the material prior to testing, it is possible to deduce that the friction-produced hardening is not as considerable as it is with the Hastelloy C. The data from the curves reveal another noticeable difference: a greater hardness in the track means an increased mass loss.

This material average rugosity, $\mathrm{Ra}$, as measured in the wear tracks, presents values comparable to those obtained for the Hastelloy C. However, for the Refractalloy 26, the $\mathrm{Rz}$ values that indicate profile irregularity are more constant among the different samples and they are also noticeably lower. In Figure 1(d), the Rz values have been multiplied by a factor of 5. It is also possible to observe that an increase in hardness is accompanied by a decrease in the rugosity, as well as a more uniform rugosity profile (the values of $\mathrm{Ra}$ and $\mathrm{Rz}$ go down).

In Figure 2, there is a comparison of the microstructures of the Hastelloy C and Refractalloy 26. These samples had not yet undergone wear, but had already been subjected to 


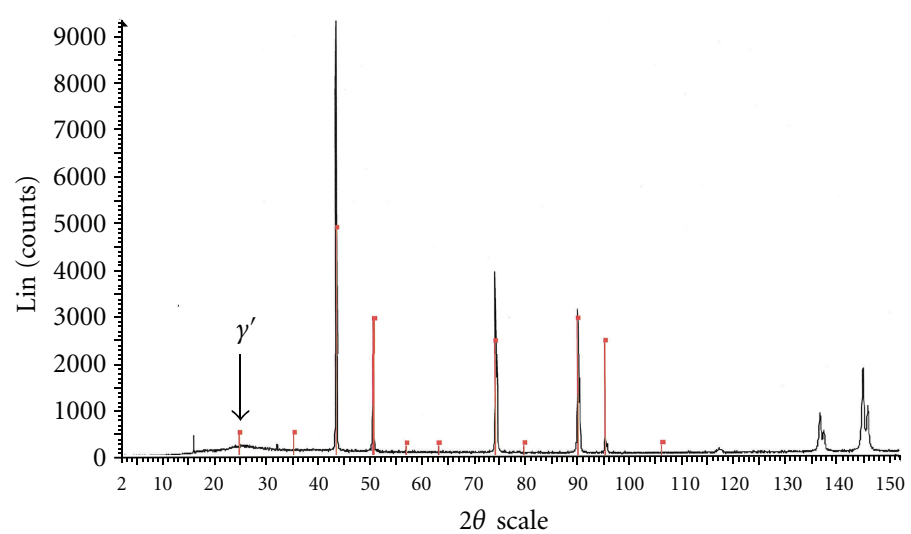

(a)

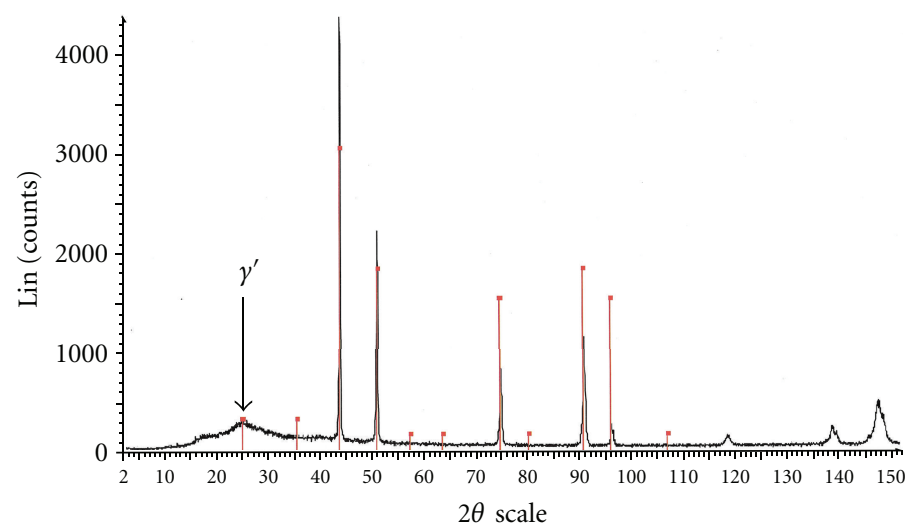

(b)

FIGURE 3: X ray diffraction (XRD) of Hastelloy C (a) and Refractalloy 26 (b) as cast. Gamma and $\gamma^{\prime}$ phases show the same main peaks $(2 \theta=43.75,50.97,74.96$ and 91.05 degrees $)$. Gamma prime phase shows a very weak extra peaks at $2 \theta=24.85$ degrees.

the $400^{\circ} \mathrm{C}$ thermal cycle (heated to $400^{\circ} \mathrm{C}$ for 75 minutes and then slowly cooled to ambient temperature).

Initially the Hastelloy $\mathrm{C}$ shows an austenite structure typical of nickel alloys. $\mathrm{Ni}_{3}$ (TiAl) precipitates ( $\gamma^{\prime}$ phase) are also present. This phase was detected by X-ray diffraction (XRD) (Figure 3). Although the diffraction patterns of $\gamma$ and $\gamma^{\prime}$ phases have the same main peaks $(2 \theta=43.75,50.97$, 74.96 , and 91.05 degrees), the last one shows very weak extra peaks (the most intense of them appears at $2 \theta=24.85$ degrees). Once it is heated to and kept at $400^{\circ} \mathrm{C}$, the number of fine precipitates grows considerably.

Similarly, the microstructure of the Refractalloy 26 has an austenite graining, but there are more $\mathrm{Ni}_{3}(\mathrm{TiAl})$ precipitates (Figure 3). When the sample undergoes the thermal cycle for the $400^{\circ} \mathrm{C}$ wear test, it is also obvious that the number of precipitates noticeably grows, although they are not uniformly distributed. Moreover, they are not as fine as the ones in the Hastelloy C.

\section{Discussion}

Figure 4 compares the results for the mass loss in the wear test, the track hardness, and the rugosity uniformity obtained for the Hastelloy C and Refractalloy 26.

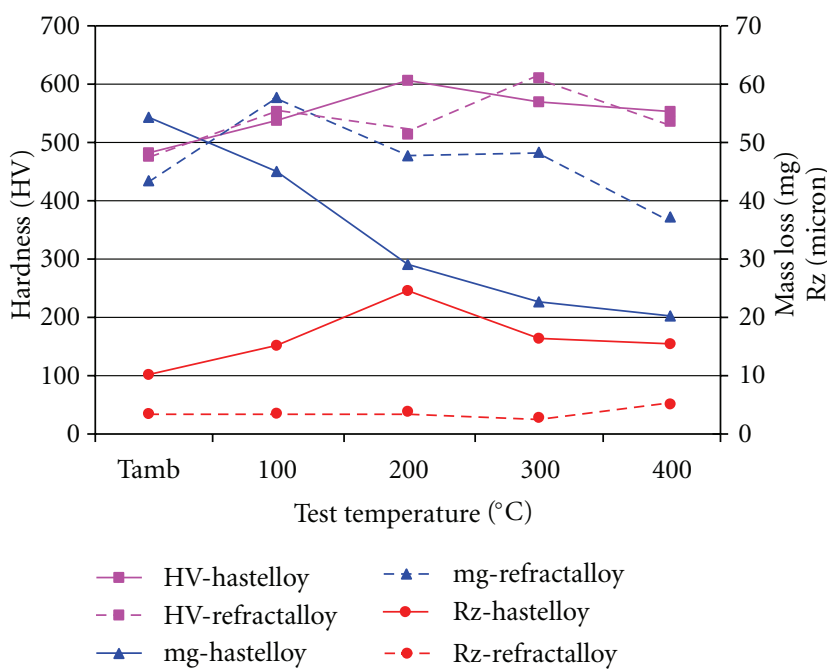

FIGURE 4: Comparison of the results for wear, hardness and rugosity for the Hastelloy C and Refractalloy 26.

The hardness value of Hastelloy C subjected to friction is noticeably higher than that of the nontested material. It is comparable to the values presented in the wear tracks of the 
Refractalloy 26, which experienced a slight increase from the initial hardness value.

If one studies the results for the mass loss in both materials, one can see that the wear resistance of the Refractalloy 26 is less even though similar hardness values are reached. According to the metallographic study of the Refractalloy 26 , the precipitates that appear as a consequence of the temperature increase are not as uniform in their distribution. They are larger than those in the Hastelloy C. The presence of the finer precipitates and the friction-produced hardness explain why the Hastelloy $\mathrm{C}$ behaves well when it is subjected to wear.

In the Refractalloy 26, the larger precipitates might be seen as the reason for an increase in the mass loss during wear testing, given that the particles could detach from the alloy and, as the test was done without lubrication, act like an abrasive, increasing wear [8]. The polishing action of the detached precipitates would also cause less irregularity in the rugosity profile of the wear tracks. This would imply that the $\mathrm{Rz}$ values are slightly lower in the Refractalloy 26 than they are in the Hastelloy C.

\section{Conclusions}

This study examined the interplay between wear, hardness, and metallographic properties at different temperatures of two nickel-base alloys, Hastelloy C and Refractalloy 26.

The hardness of the Hastelloy $\mathrm{C}$ before testing is much lower than that of the Refractalloy 26. Nevertheless, Hastelloy $\mathrm{C}$ hardness stands out due to the friction forces it withstands during the wear testing at a range of temperatures. The hardness observed for the Refractalloy 26 is much lower. The hardness values that are measured in the wear after the pin on disk tests are comparable for both materials.

Prior to treatment, the microstructure of the two alloys is typical of nickel-base alloys, with austenite grain and the presence of a few precipitates. The difference lies in the greater number of precipitates found in the Refractalloy 26.

When the alloys are subjected to the thermal cycles for the wear (heated to the testing temperature for 75 minutes and then gradually cooled), they display a higher number of precipitates. The Hastelloy $\mathrm{C}$ precipitates are uniform and have fine particles. The Refractalloy 26 precipitates are less uniform and have a larger particle.

The Hastelloy $\mathrm{C}$ has a higher resistance to wear because of the hardening it experiences when subjected to friction forces. This resistance increases as the testing temperature is made higher.

The Refractalloy 26 behaves very differently. It presents less resistance to wear than the Hastelloy $C$, and its wear resistance decreases as the hardness increases. This behavior, along with the distribution and size of the precipitates observed in the metallographic structure of the alloys subjected to thermal treatment, indicates that the particles detached during the wear process play a role as an abrasive.

In both cases, the friction coefficient seen in the wear tests reveals the same trend as the mass loss measured during the tests.
The rugosity found in the wear tracks is less and the rugosity profile is more regular in the Refractalloy 26 due to the abrasive action of the particles that detach during the wear process.

\section{References}

[1] L. Yingjie, B. Xingui, and C. Keqiang, "A study on the formation of wear debris during abrasion," Tribology International, vol. 18, no. 2, pp. 107-111, 1985.

[2] H. Berns, A. Fischer, and S. D. Franco, Congresso Anual Associacao Brasileira de Metalurgia e Materiais, 1995.

[3] X. Xu, Y. Yu, and H. Huang, "Mechanisms of abrasive wear in the grinding of titanium (TC4) and nickel (K417) alloys," Wear, vol. 255, no. 7-12, pp. 1421-1426, 2003.

[4] B. Bouaifi and U. Draugelates, "Precipitation-hardenable nickel-based super alloys for wear resistance in the high-temperature range," Materials and Corrosion, vol. 54, no. 12, pp. 988-994, 2003.

[5] U. Wende, B. Bouaifi, S. Bauer, and A. Bock, "Auftragschweißen mit ausscheidungshärtbaren Nickelbasis-Superlegierungen für den Verschleißschutz im Hochtemperaturbereich," DVS-Berichte, vol. 220, pp. 84-93, 2002.

[6] "Standard test method for wear testing with a pin-on-disk apparatus," in Annual Book of ASTM Standars, vol. 03.02 of ASTM G99-05, pp. 408-412, ASTM International, 2008.

[7] G. F. Vander Voort, Metallography: Principles and Practice, McGraw-Hill, 1984.

[8] K. Yang, S. Yu, Y. Li, and C. Li, "Effect of carbonitride precipitates on the abrasive wear behaviour of hardfacing alloy," Applied Surface Science, vol. 254, no. 16, pp. 5023-5027, 2008. 

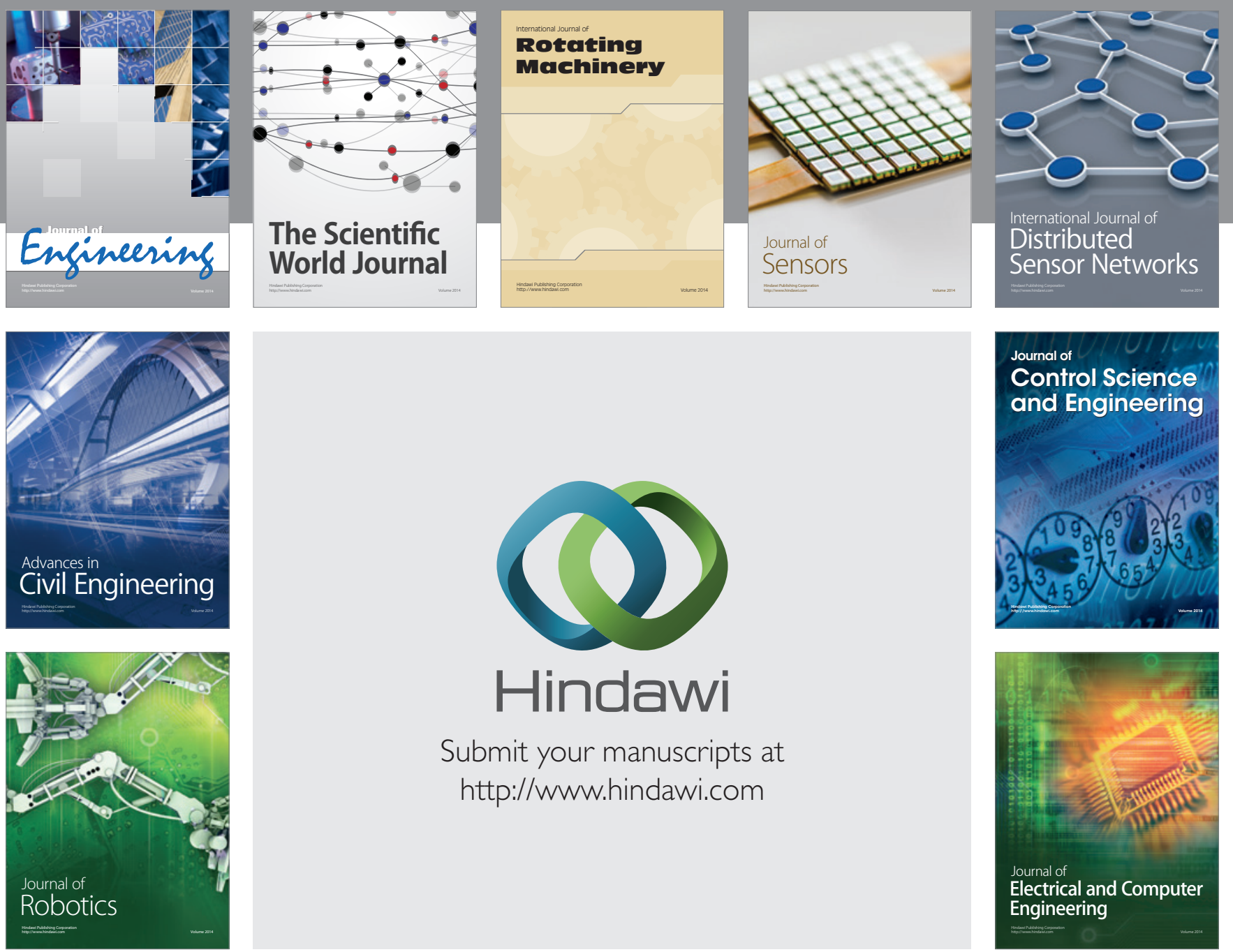

Submit your manuscripts at

http://www.hindawi.com
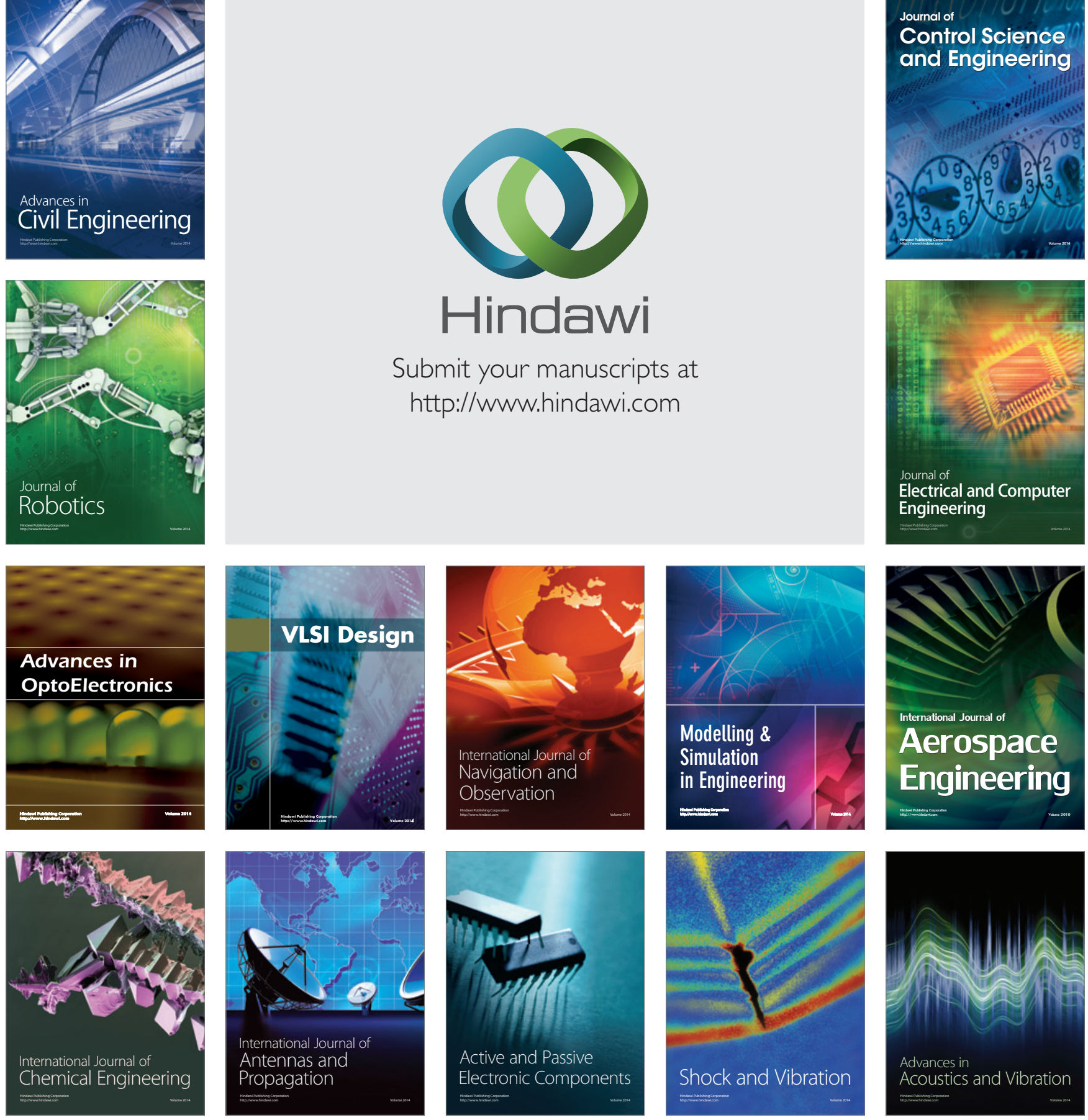